
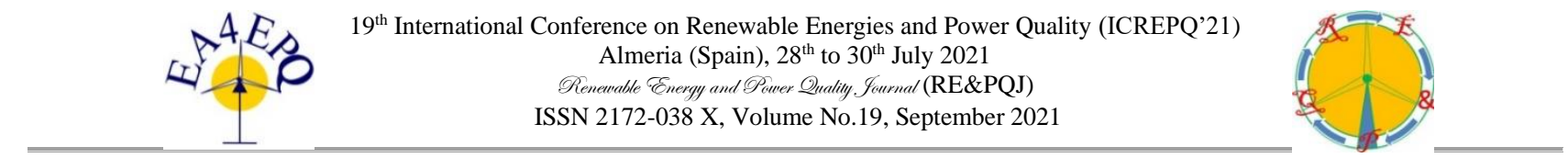

\title{
Fast testing platform for the isolation transformer
}

\author{
G. Bucci ${ }^{1}$, F. Ciancetta ${ }^{1}$, A. Fioravanti ${ }^{1}$, E. Fiorucci ${ }^{1}$, S. Mari ${ }^{1}$ and A. Prudenzi ${ }^{1}$ \\ ${ }^{1}$ Department of Industrial and Information Engineering and Economics \\ University of L'Aquila \\ Monteluco di Roio, 67100, L'Aquila (Italy) \\ e-mail: andrea.fioravanti@graduate.univaq.it
}

\begin{abstract}
This work shows a program created in a Labview environment to verify the correct functioning and regulatory compliance of isolation transformers and isolation transformers for medical use. The transformer tests will be divided into acceptance tests and type tests. For each type of test, the program will be able to provide information for correct testing and to speed up the test path.The guided test procedure will accompany the author up to the automatic printing of the test reports. Finally, considerations will be made on which tests to perform on already installed transformers that require recertification.
\end{abstract}

Key words. Isolation transformers; test platform; medical use transformers; fast testing;

\section{Introduction}

Isolation transformers, usually installed between the power input and the device to be protected [1], provide electrical separation of the earth connection and thus eliminate the circuit that could be created between mass and ground. In test instruments, the insulation between primary and secondary eliminates the short between the probe input and the earth circuit; it also filters out high frequency noise that can travel on $\mathrm{AC}$ lines causing problems for sensitive transducers and instruments [2]. Isolation transformers are electrical machines often used in low voltage electrical systems for functional and safety reasons. These must comply with stringent regulations, which can be analyzed through repetitive tests in order to certify the quality and compliance for use $[3,4]$.

The isolation transformer that is for general (IT) or medical (IT-M) use is a transformer that has a double or reinforced insulation between the windings or a metal shield connected to earth for the protection separation, to avoid contact between primary and secondary [5].

Usually, the primary and secondary windings are concentric wounds separated by an insulating layer and a Faraday shield [6]. The latter can be implemented as a layer made from copper or aluminum foil connected to earth to the primary. The double insulation of these transformers is therefore guaranteed by the enameled wire and by the insulating layer between primary and secondary [7].

Compared to the normal transformer, which already guarantees galvanic isolation, there is greater isolation capable of guaranteeing greater safety, given the lower leakage currents [8].

These transformers are used to ensure protection by electrical separation in IT systems and therefore ensure safety against indirect contacts (contact with a ground or conductive part connected to the ground during an insulation fault).

In the second paragraph, a brief mention will be given on the operation of electrical safety transformers and on the main characteristics of isolation transformers. In the third paragraph, the field of application of the platform will be framed and the tests will be briefly treated, dividing them into acceptance tests and type tests. The fourth paragraph shows the platform developed in our laboratory thanks to the NI LabVIEW software. The operational characteristics of the proposed system have been verified by extensive measurements made in the laboratory on multiple isolation transformers [9].

\section{Isolation transformer}

The transformer is a static electrical appliance that is used for the conversion of energy, specifically from electrical energy with certain values of voltage and current to energy always electric, with equal frequency, but with different voltage and current values compared to the previous ones through two windings with a different number of turns.

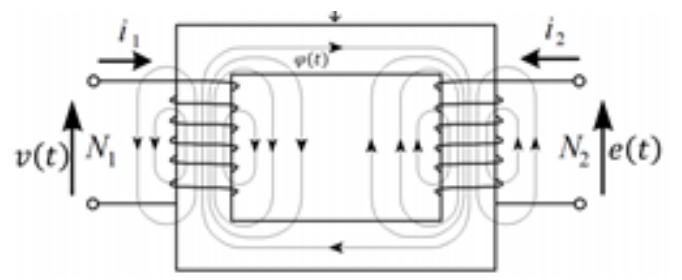

Fig.1. Simplified diagram of a transformer

The alternating current circulating in the primary creates a magnetic field $\widetilde{\boldsymbol{H}}$ which is mostly confined to the ferromagnetic core. The magnetic induction $\widetilde{\boldsymbol{B}}$ created 
will in turn give rise to a time-varying magnetic flux $\boldsymbol{\varphi}(\boldsymbol{t})$ which will circulate in the core. According to Faraday's law, an induced electromotive force $\boldsymbol{e}(\boldsymbol{t})$ arises on the secondary winding which can give rise to the secondary current if the circuit is closed on a load.

$$
\begin{gathered}
\vec{B}(t)=\mu * \vec{H}(t) \\
\varphi(t)=\int_{S} \vec{B} * \vec{n} d S \\
e(t)=-N_{2} \frac{d \varphi}{d t}
\end{gathered}
$$

In the case of isolation transformers, the transformation ratio is usually unitary.

The fundamental advantage of an isolation transformer is the galvanic isolation between primary and secondary. This occurs under ideal conditions with ideal insulation materials.

The current flowing through the insulating material is differentiated into:

- Leakage current: In the presence of air, a small concentration of atoms or particles of matter is sufficient to give rise to the birth of ions. These, under the action of an electric field, constitute a conduction current called leakage current. This also applies to liquid or solid insulating media. This current is therefore due to the ordered motion of the free charges in the insulation, it is a characteristic that distinguishes each material and is also a constant current over time;

- Capacitive type current: Each insulating material, or dielectric in general, has a welldefined capacity that is electrically charged when subjected to a voltage. For the capacitor charging process there is a current absorption, precisely of the capacitive type, which will be maximum in the initial instants and will decrease over time as the capacity is charged;

- Absorption current: The internal structure of the insulating materials is constituted by molecules forming electric dipoles which in general and in the absence of an electric field are oriented in a completely random and disordered way. By applying an electric field to the ends of the insulation, the dipoles orient themselves like the field and absorb energy, which is returned by subsequently removing the electric field.

The sum of these currents is not constant but will have a maximum as soon as the transformer is powered and it will settle at the nominal value after a few minutes. In the isolation transformers, this value must be lower than a threshold imposed by the technical standards and must be verified through specific tests.

\section{A. Isolation transformers for medical use}

The differences, given the use in different environments, between the isolation transformer for general use and the one for medical use are defined in parts $2-4$ and 2-15 of the CEI-EN 61558 standard. A substantial difference is in the leakage currents, which in the transformer for medical use must be lower.

The IT-M systems are always systems with isolated star point and the $\mathrm{M}$ indicates the specific application for the medical sector [10].

\section{Acceptance and type tests}

The CEI-EN 61558 standard defines the acceptance tests in Annex L and the type tests from Article 8.15 to Article 28 [11].

For technical and practical reasons, the acceptance tests are the first on the list, since they are the first to be performed. Table 2.1 shows the most important tests to be performed on each machine: the letter $(\mathrm{T})$ indicates the type tests and the letter (A) the acceptance tests.

In the presence of sub-tests, the main test is passed only

\begin{tabular}{|c|c|c|c|}
\hline $\begin{array}{c}\text { Test } \\
\text { number }\end{array}$ & Test & Under-test & Typology \\
\hline 1 & $\begin{array}{l}\text { Conformity of plate } \\
\text { data; }\end{array}$ & & A \\
\hline 2 & $\begin{array}{l}\text { Ground connection } \\
\text { continuity test }\end{array}$ & & A \\
\hline 3 & $\begin{array}{l}\text { Check of the secondary } \\
\text { voltage in no-load } \\
\text { condition }\end{array}$ & & $\mathrm{T}$ \\
\hline 4 & Dielectric strength test & & A \\
\hline 5 & $\begin{array}{l}\text { Verification of } \\
\text { assembly of protective } \\
\text { devices }\end{array}$ & & A \\
\hline 6 & $\begin{array}{l}\text { Check the short-circuit } \\
\text { voltage (IT-M) }\end{array}$ & & A \\
\hline 7 & $\begin{array}{l}\text { Verification of the } \\
\text { primary no-load current } \\
\text { (IT-M) }\end{array}$ & & A \\
\hline 8 & $\begin{array}{l}\text { Checking the inrush } \\
\text { current (IT-M) }\end{array}$ & & A \\
\hline 9 & $\begin{array}{l}\text { Indelible and legible } \\
\text { marking }\end{array}$ & & $\mathrm{T}$ \\
\hline 10 & 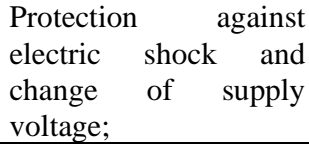 & & $\mathrm{T}$ \\
\hline 10.1 & & $\begin{array}{l}\text { Determination of } \\
\text { dangerous live parts }\end{array}$ & $\mathrm{T}$ \\
\hline 10.2 & & $\begin{array}{l}\text { Accessibility r to } \\
\text { non-dangerous live } \\
\text { parts }\end{array}$ & $\mathrm{T}$ \\
\hline 10.3 & & $\begin{array}{lr}\text { Accessibility to } \\
\text { dangerous live parts }\end{array}$ & $\mathrm{T}$ \\
\hline 10.4 & & $\begin{array}{l}\text { Changing the power } \\
\text { supply voltage }\end{array}$ & $\mathrm{T}$ \\
\hline 11 & $\begin{array}{l}\text { Secondary voltage and } \\
\text { secondary current } \\
\text { under load; }\end{array}$ & & $\mathrm{T}$ \\
\hline
\end{tabular}
if all the sub-tests are positive.

Table I. - Type and acceptance test of IT and IT-M 


\begin{tabular}{|c|c|c|c|}
\hline 12 & $\begin{array}{|ll|}\begin{array}{l}\text { No-load } \\
\text { voltage }\end{array} & \text { secondary } \\
\end{array}$ & & $\mathrm{T}$ \\
\hline 13 & $\begin{array}{l}\text { Short-circuit voltage } \\
\text { and inrush currents }\end{array}$ & & $\mathrm{T}$ \\
\hline 13.1 & & $\begin{array}{l}\text { Measurement of } \\
\text { short-circuit voltage }\end{array}$ & $\mathrm{T}$ \\
\hline 13.2 & & $\begin{array}{l}\text { Measurement of } \\
\text { primary current in } \\
\text { no-load condition }\end{array}$ & $\mathrm{T}$ \\
\hline 13.3 & & $\begin{array}{ll}\begin{array}{l}\text { Measurement } \\
\text { inrush current }\end{array} & \text { of } \\
\end{array}$ & $\mathrm{T}$ \\
\hline 14 & $\begin{array}{l}\text { Measurement of } \\
\text { winding and insulating } \\
\text { temperature, contact } \\
\text { current measurement, } \\
\text { current measurement of } \\
\text { the protective earth } \\
\text { conductor }\end{array}$ & & $\mathrm{T}$ \\
\hline 15 & $\begin{array}{lr}\text { Accelerated aging test } \\
\text { for } & \text { undeclared } \\
\text { insulation } & \\
\end{array}$ & & $\mathrm{T}$ \\
\hline 15.1 & & Heat Test & $\mathrm{T}$ \\
\hline 15.2 & & Vibration test & $\mathrm{T}$ \\
\hline 15.3 & & Moisture test & $\mathrm{T}$ \\
\hline 16 & $\begin{array}{l}\text { Short circuit and } \\
\text { overload protection }\end{array}$ & & $\mathrm{T}$ \\
\hline 16.1 & & Short circuit test & $\mathrm{T}$ \\
\hline 16.2 & & Overload test & $\mathrm{T}$ \\
\hline 17 & Mechanical resistance & & \\
\hline 18 & $\begin{array}{l}\text { Protection against } \\
\text { harmful penetration of } \\
\text { dust, solid bodies and } \\
\text { humidity }\end{array}$ & & $\mathrm{T}$ \\
\hline 19 & $\begin{array}{l}\text { Insulation resistance, } \\
\text { dielectric strength and } \\
\text { leakage current }\end{array}$ & & $\mathrm{T}$ \\
\hline 19.1 & & $\begin{array}{l}\text { Measurement of } \\
\text { insulation } \\
\text { resistance }\end{array}$ & $\mathrm{T}$ \\
\hline 19.2 & & $\begin{array}{l}\text { Dielectric strength } \\
\text { test }\end{array}$ & $\mathrm{T}$ \\
\hline 20 & Construction audits & & $\mathrm{T}$ \\
\hline 21 & $\begin{array}{l}\text { Conformity } \\
\text { components }\end{array}$ & & $\mathrm{T}$ \\
\hline 22 & Internal wiring checks & & $\mathrm{T}$ \\
\hline 23 & $\begin{array}{l}\text { Network connection or } \\
\text { other flexible cables }\end{array}$ & & $\mathrm{T}$ \\
\hline 24 & $\begin{array}{l}\text { Conformity } r \text { of } \\
\text { terminals for external } \\
\text { conductors }\end{array}$ & & $\mathrm{T}$ \\
\hline 25 & $\begin{array}{ll}\begin{array}{l}\text { Compliance } \\
\text { protective earth }\end{array} & \text { on } \\
\end{array}$ & & $\mathrm{T}$ \\
\hline 26 & $\begin{array}{l}\text { Conformity of screws } \\
\text { and connections }\end{array}$ & & $\mathrm{T}$ \\
\hline 27 & $\begin{array}{l}\text { Surface distances, in } \\
\text { the air and through the } \\
\text { insulation }\end{array}$ & & $\mathrm{T}$ \\
\hline 28 & $\begin{array}{l}\text { Resistance to heat, fire } \\
\text { and surface currents }\end{array}$ & & $\mathrm{T}$ \\
\hline 28.1 & & $\begin{array}{l}\text { Verification of heat } \\
\text { resistance }\end{array}$ & $\mathrm{T}$ \\
\hline 28.2 & & $\begin{array}{l}\text { Verification of heat } \\
\text { resistance in fault } \\
\text { conditions }\end{array}$ & $\mathrm{T}$ \\
\hline 28.3 & & $\begin{array}{l}\text { Verification of fire } \\
\text { resistance }\end{array}$ & $\mathrm{T}$ \\
\hline
\end{tabular}

\begin{tabular}{|c|l|l|c|}
\hline 28.4 & $\begin{array}{l}\text { Verification of } \\
\text { surface currents }\end{array}$ & $\mathrm{T}$ \\
\hline 29 & Protection against rust & & $\mathrm{T}$ \\
\hline
\end{tabular}

The acceptance tests are the first 8 but tests 6,7 and 8 must be done only for the IT-M transformers. These must be done on all transformers as they can report any anomalies without affecting the integrity or reliability of the machine. The type tests must be carried out for each batch of identical transformers with the same code and same characteristics. To be carried out, selections must be made from or more transformers which will be demolished during the test.

\section{Software for fast testing}

Given a large number of tests and the difficulty in carrying out all the tests, it was decided to develop software to assist the tester.

This section will therefore present a support program for testing isolation and electromedical isolation transformers.

Once the general data of the device under tests (DUT) and other required parameters have been entered, it is possible to carry out the acceptance tests in a simple and guided way, having, at the end of the execution of the tests, the possibility of automatically printing the test report with all the results and values measured during the tests.

The program was created in the NI LabVIEW environment, developing the code through the two connected visual development pages "Front Panel" and "Block Diagram". The graphic programming allows easy and fast development of the software and subsequent debugging of the same.

The core of the algorithm was developed through the use of an "Event State Machine" so that future developments can be made through the implementation of small pieces of code.

On the user interface developed graphically on the front panel, at the start of the program the user name and password of the tester must be entered to avoid changes to the test data by external personnel (having the final declarations legal value).

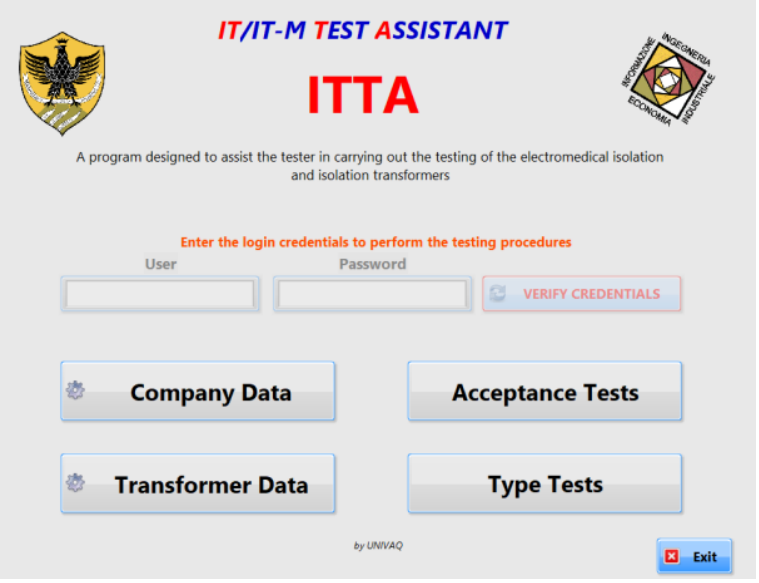

Fig.2. Home page screen 
The four buttons below allow the user to access:

- company data: here are the data of any customer of the test and these data will appear on the final bulletin.

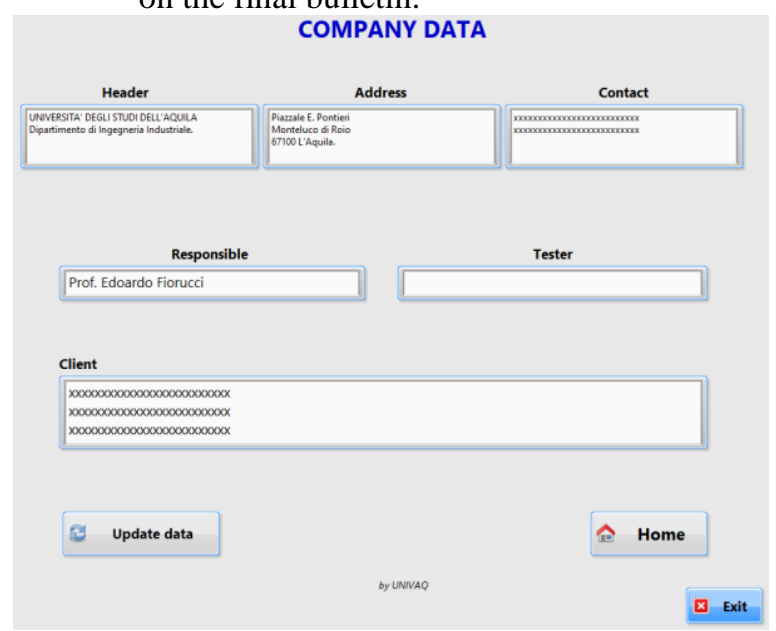

Fig.3. Company data screen

- transformer data: where all the essential information for carrying out the tests is entered and which enable the various test phases based on the type of DUT.

- Acceptance tests: this button directs the user to the real acceptance test wizard, shown in fig. 5.

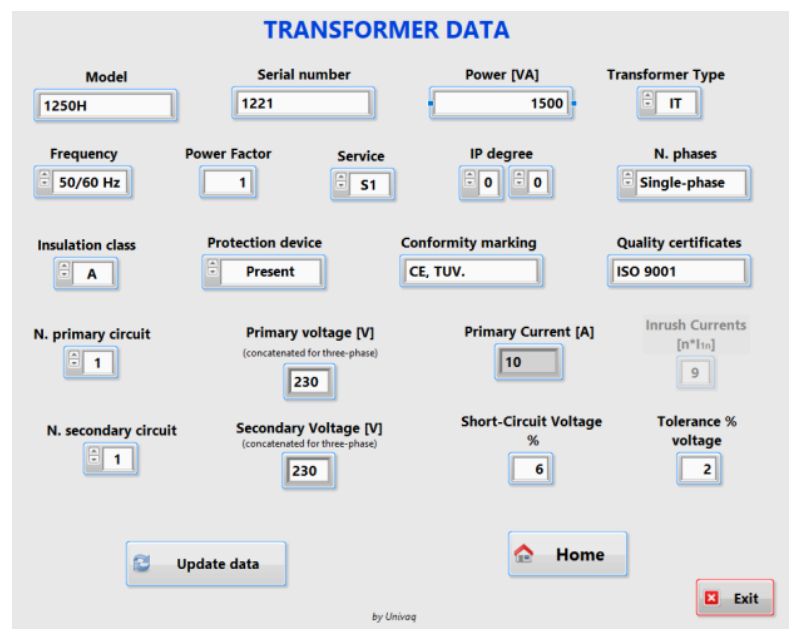

Fig.4. Transformer data screen

The fundamental data that must be entered on "transformer data" are: "Model", "Serial number" and "Transformer type". The first two data are used to create the temporary files for saving the results of the tests and the data entered during the procedures, while the third data is used to activate or deactivate the control of the inrush currents and activate and deactivate tests 6, 7 and 8 which are dedicated only to IT-M transformers. Numeric values can be entered in the relevant boxes from the keyboard and in others, using the mouse, the right wording must be chosen from a preset list. These data are then analyzed and other information necessary for the program, such as currents, is calculated.

With the "Acceptance tests" button, the user enters the wizard for acceptance testing. The 5 or 8 trial procedure was made rigid. When started, all tests must be completed to return to the initial screen and the next test can only be passed after saving the added data. In this procedure, we have preferred to use multiple answers (yes and no) and the user is required to enter only a few data manually.

In the upper part of the user interface, we find the keys that allow you to open the legislation concerning the test in question in pdf format and the description of the procedure with the equipment to be used.

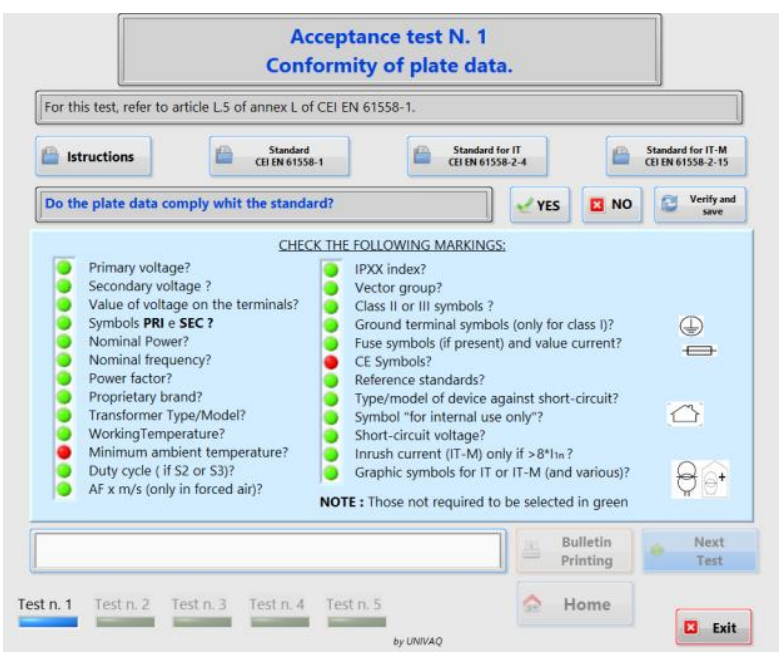

Fig.5. Acceptance tests: test n.1

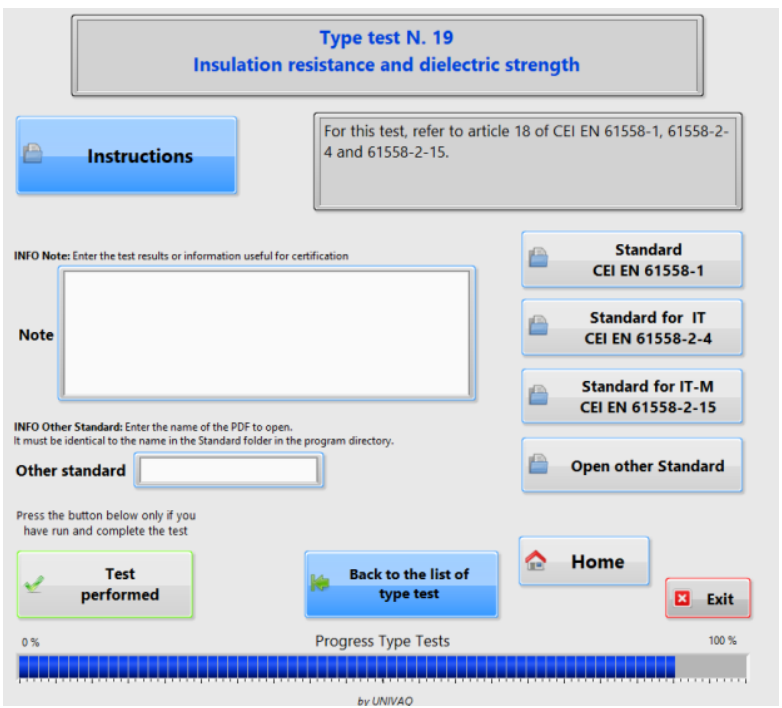

Fig.6. Type tests: test n.19

The test report saved in PDF in a specific folder can be printed directly from the Labview program at the end of the whole procedure. It contains data such as manufacturer and model of the transformer and information on the tester. In addition, the entire list of tests carried out with the results obtained is shown and any notes at the bottom of the page. This bulletin will then be attached to the transformer and bagged with it if the tested transformer is a commercial product. 


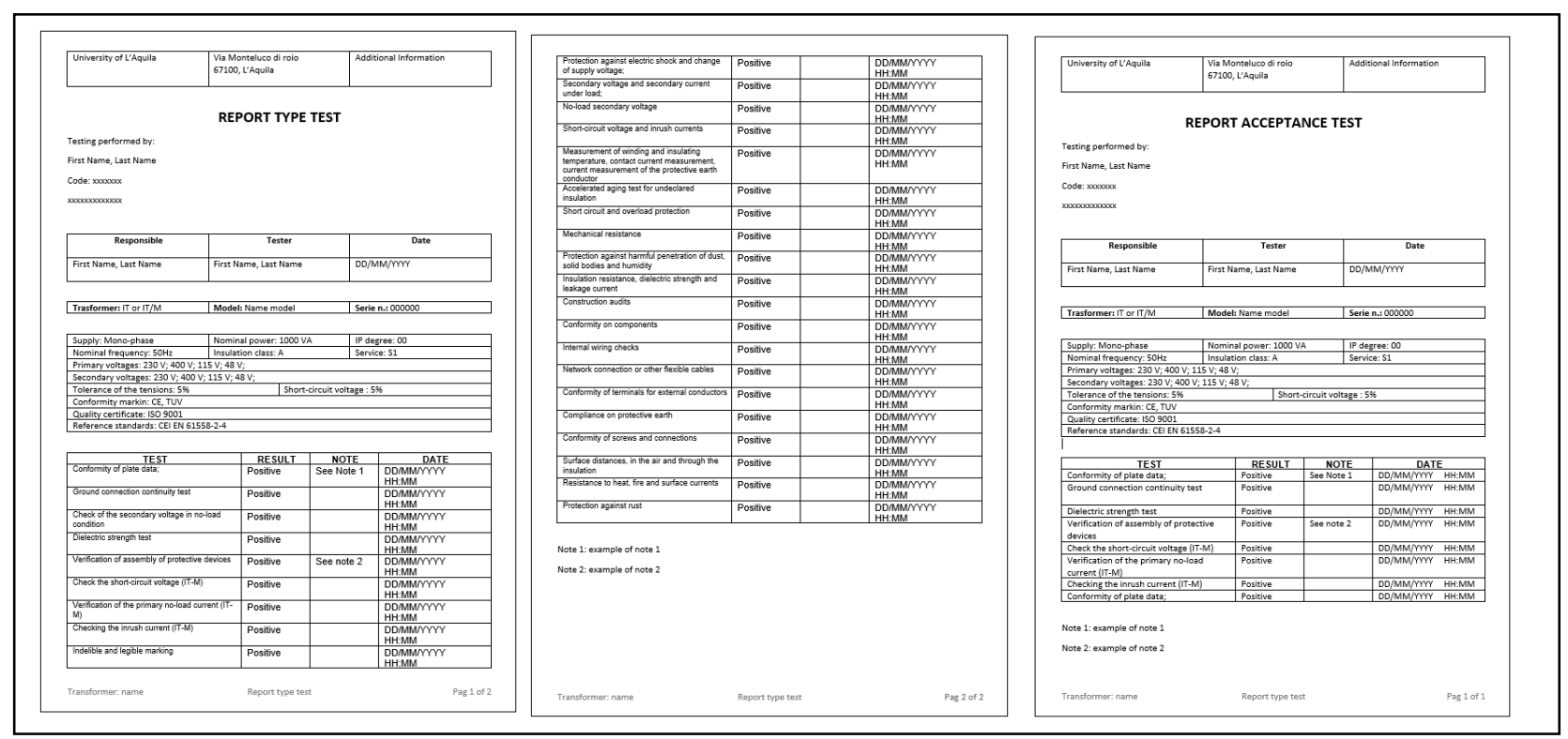

Fig. 7. Test reports for type tests and acceptance tests

\section{Conclusion}

Isolation transformers are an important element of the system especially when it is necessary to increase the safety of the electrical user systems. Isolation transformers for medical use are widely used in hospitals and health centers as they are mounted both for powering operating rooms and inside electro-medical equipment [12].

Most of the work focused on developing a test platform that would make testing transformers quick and easy [13]. After having analyzed the regulations in force, research was carried out on the test methods and instruments. Some tests for simplicity have been merged under a single test as they provided for the use of the same test scheme or it was easy to process at the same time. This reduced the number of tests with the disadvantage of a minimal lengthening of the test duration.

In the development of the software to assist the tester, all the acceptance tests were made rigid and consecutive to speed them up and to avoid errors if the software were used repeatedly in the production phase.

For the type tests, however, greater freedom was left on how and when to perform the tests, also because some tests also have a duration of more than $24 \mathrm{~h}$ and therefore the tester can move between them to update the data of several DUTs in parallel.

During the tests, the tester is able to analyze the various standards that describe the test, to analyze the test systems he must use and can save notes which will then be published and reported in the test bulletin.

The choice of the LabVIEW language for the development of this software is due to the possibility of making the program interact with the various multibrand hardware equipment to carry out the tests automatically and create a real specific test bench.

\section{References}

[1] R. W. Jones, "Application of isolation transformers for paper machine DC drives-a service perspective," Conference Record of 1988 Annual Pulp and Paper Industry Technical Conference, Milwaukee, WI, USA, 1988, pp. 145-, doi: 10.1109/PAPCON.1988.10918.

[2] M. A. Shafie, H. Singh and M. Q. A. Rahman, "Harmonic and neutral to ground voltage reduction using isolation transformer," 2010 IEEE International Conference on Power and Energy, Kuala Lumpur, Malaysia, 2010, pp. 561-566, doi: 10.1109/PECON.2010.5697645.

[3] Y. Zhao, G. Zhang, K. Li, Y. Liu and F. Yang, "A Test Standard for Winding Insulation and Air Gaps of DryType HV-HF Transformer," 2019 22nd International Conference on Electrical Machines and Systems (ICEMS), Harbin, China, 2019, pp. 1-5, doi: 10.1109/ICEMS.2019.8922144.

[4] V. Yalentić, S. Gržinić and D. Dobrec, "Testing the electrical insulation system of power transformer based on mesuring factor of dielectric losses," IEEE EUROCON $2017-17$ th International Conference on Smart Technologies, Ohrid, 2017, pp. 423-427, doi: 10.1109/EUROCON.2017.8011146.

[5] M. Jaritz and J. Biela, "Isolation design of a $14.4 \mathrm{kV}$, $100 \mathrm{kHz}$ transformer with a high isolation voltage (115kV)," 2016 IEEE International Power Modulator and High Voltage Conference (IPMHVC), San Francisco, CA, 2016, pp. 73-78, doi: 10.1109/IPMHVC.2016.8012831.

[6] Art Pini, "Principi base dei trasformatori di isolamento, come sceglierli e usarli", 2020-05-20, site: https://www.digikey.it/it/articles/the-basics-of-isolationtransformers-and-how-to-select-and-use-them visited on $08 / 02 / 2021$

[7] C. Boonseng, R. Boonseng and K. Kularbphettong, "The Low Voltage Isolation Transformer Failure Investigation: 
Measurements, Analysis and Lessons Learned," 2020 International Conference on Diagnostics in Electrical Engineering (Diagnostika), Pilsen, Czech Republic, 2020, pp. 1-4, doi: 10.1109/Diagnostika49114.2020.9214603.

[8] Bucci G., Ciancetta F., Fioravanti A., Fiorucci E., Prudenzi A. "Improving the power system safety in hospitals by means of periodical sfra tests on medical isolation transformers", Renewable Energy and Power Quality Journal, 2020, 18, pp. 282-286, 300, doi: 10.24084/repqj 18.300

[9 ]F. Ciancetta, G. Bucci, E. Fiorucci, S. Mari and A. Fioravanti, "A New Convolutional Neural Network-Based System for NILM Applications," in IEEE Transactions on Instrumentation and Measurement, vol. 70, pp. 1-12, 2021, Art no. 1501112, doi: 10.1109/TIM.2020.3035193.

[10] Bucci G., Ciancetta F., Fioravanti A., Fiorucci E., Prudenzi A., "Application of SFRA for diagnostics on medical isolation transformers", International Journal of Electrical Power and Energy Systems, 2020, 117, 105602, doi: 10.1016/j.ijepes.2019.105602

[11] CEI - EN 61558: Safety of power transformers, power supplies, reactors and similar products

[12] Prudenzi A., Fioravanti A., Regoli M., “A low-cost iot solution for power availability improvement in hospitals", Renewable Energy and Power Quality Journal, Volume 1, Issue 16, April 2018, Pages 566-571, doi: 10.24084/repqj16.389

[13] Prudenzi A., Fioravanti A., Pierannunzi F., Ciancetta F., "Distributed Power Quality monitoring in customer's electrical distribution system", 19th IEEE International Conference on Environment and Electrical Engineering and 2019 IEEE Industrial and Commercial Power Systems Europe, EEEIC/I and CPS Europe 2019; Genoa (Italy); 11 June 2019 through 14 June 2019, doi: 10.1109/EEEIC.2019.8783784 